proximal ICA. Various combinations of internal support were investigated 1) $2.1 \mathrm{~F}$ microcatheters and 0.014" microwire, 2) $6 \mathrm{~F}$ aspiration catheters. Where additional support was required to cross the ophthalmic artery, microcatheters of up $2.7 \mathrm{~F}$ or Penumbra 3Max and/or a 0.016" microwire were used.

Results Varying tortuosity was encountered; aortic-arch (Type IIII, bovine), cervical (s-shaped); siphon (U, C, S, $\Omega$ ). In 11/12 instances it was possible to navigate to the distal M1 using test (Millipede 088) and control (6F aspiration catheters) devices. In the instance of unsuccessful navigation, both Millipede 088 and the $6 \mathrm{~F}$ aspiration catheters were unable to cross the ophthalmic artery. In general, navigation of Millipede 088 to the M1 was facilitated by the support of a $6 \mathrm{~F}$ aspiration catheter.

Conclusions Navigation of the Millipede 088 catheter to the M1 is feasible in a cadaver model. The ophthalmic artery can represent a challenge which in the majority of cases can be overcome using the support of standard neurovascular devices. Disclosures R. Nogueira: 2; C; Perfuze Ltd. 4; C; Perfuze. L. Mullins: 4; C; Perfuze Ltd. 5; C; Perfuze Ltd. D. Finneran: 4; C; Perfuze Ltd. 5; C; Perfuze Ltd. W. Allen: 4; C; Perfuze Ltd. 5; C; Perfuze Ltd. J. Thornton: 2; C; Perfuze Ltd. 4; C; Perfuze Ltd.

\section{E-062 IMPACT OF ANGIOGRAPHIC APPEARANCE OF PROXIMAL MIDDLE CEREBRAL ARTERY OCCLUSION ON FIRST PASS REPERFUSION}

M Mohammaden*, D Haussen, L Pisani, A Al-Bayati, S Belagaje, N Bhatt, M Frankel, R Nogueira. Marcus Stroke and Neuroscience Center, Grady Memorial Hospital and Department of Neurology, Emory University School of Medicine, Atlanta, GA

\subsection{6/neurintsurg-2020-SNIS.98}

Background and Purpose The first pass effect (FPE) is a key predictor of clinical outcome after mechanical thrombectomy (MT) for large vessel occlusion stroke (LVOS). We aim to study the impact of initial angiographic appearance of middle cerebral artery (MCA) occlusion on FPE.

Methods A prospectively maintained MT database from January 2018 to December 2019 was reviewed. Patients with M1 segment MCA occlusion were included. FPE was defined as complete reperfusion (mTICI2c-3) after a single pass thrombectomy. Occlusion site angiographic appearance was classified into two categories; regular, when the occlusion is smooth stump with abrupt cut off and irregular which included all other types of occlusion. The primary outcomes were the

Abstract E-062 Table 1 Demographic, risk factors, procedural characteristics and outcome among regular and irregular MCA occlusion

\begin{tabular}{|c|c|c|c|c|}
\hline & All patients( $n=319)$ & Regular $(n=130)$ & Irregular(n=189) & $P$ value \\
\hline \multicolumn{5}{|l|}{ Demographics and stroke risk factors } \\
\hline Age & $65.1 \pm 16.1$ & $64.4 \pm 15.5$ & $65.7 \pm 16.5$ & 0.50 \\
\hline Female & $168(52.7)$ & $68(52.3)$ & $100(52.9)$ & 0.92 \\
\hline Hypertension & $243(76.2)$ & $101(77.7)$ & $142(75.1)$ & 0.60 \\
\hline Diabetes mellitus & $85(26.6)$ & $33(25.4)$ & $52(27.5)$ & 0.67 \\
\hline Atrial fibrillation & $103(32.3)$ & $43(33.1)$ & $60(31.7)$ & 0.80 \\
\hline Hyperlipidemia & $89(27.9)$ & $40(30.8)$ & $49(25.9)$ & 0.34 \\
\hline Current smoking & $72(22.6)$ & $37(28.5)$ & $35(18.5)$ & 0.037 \\
\hline Stroke etiology Cardioembolic & $152(47.6) 30(9.4)$ & $69(53.1) 10(7.7)$ & $83(43.9) 20(10.6)$ & 0.04 \\
\hline Large artery disease ICAD Others & $31(9.7) 106(33.2)$ & $6(4.6) 45(34.6)$ & $25(13.2) 61(32.3)$ & \\
\hline \multicolumn{5}{|l|}{ Clinical and procedural characteristics } \\
\hline LKN-Puncture & $394[217-737]$ & $442[217-726]$ & $379[211-754]$ & 0.99 \\
\hline Baseline NIHSS score & 17 [12-21] & 18 [12-21] & 17 [13-21] & 0.60 \\
\hline ASPECTS & 8 [7-9] & 8 [7-9] & 8 [7-9] & 0.24 \\
\hline Prior IV-tPA & $95(29.8)$ & $37(28.5)$ & $58(30.7)$ & 0.67 \\
\hline Favorable collaterals & $154 / 205(75.1)$ & $64 / 82(78)$ & $90 / 123(73.2)$ & 0.43 \\
\hline Left hemisphere stroke & $161(50.5)$ & $61(46.9)$ & $100(52.9)$ & 0.29 \\
\hline Tandem occlusion & $13(4.1)$ & $7(5.4)$ & $6(3.2)$ & 0.32 \\
\hline General anesthesia & 37 (11.6) & $13(10)$ & $24(12.7)$ & 0.46 \\
\hline Balloon guide catheter & $297(93.1)$ & $121(93.1)$ & $176(93.1)$ & 1.00 \\
\hline First-line technique SR CA Combined Primary intracranial stenting & $165(51.7) 43(13.5)$ & $66(50.8) 46(35.4)$ & $99(52.4) 63(33.3)$ & 0.81 \\
\hline Secondary intracranial stenting & $109(43.2) 2(0.6)$ & $18(13.8) 0(0)$ & $25(13.2) 2(1.1)$ & \\
\hline Puncture to first run & $8[6-12]$ & $8[6-12]$ & $8[6-11]$ & 0.98 \\
\hline First run to reperfusion & $35[21-59]$ & $37[21-64]$ & $33[21-53]$ & 0.14 \\
\hline Number of passes & $2[1-3]$ & $2[1-3]$ & $1[1-2]$ & 0.01 \\
\hline IA-tPA & $3(0.9)$ & $0(0)$ & $3(1.6)$ & 0.27 \\
\hline \multicolumn{5}{|l|}{ Outcome } \\
\hline FPE (mTICl2c-3) & $132(41.4)$ & $45(34.6)$ & $87(46)$ & 0.04 \\
\hline First pass successful reperfusion (mTICI2-3) & $154(48.3)$ & $52(40)$ & $102(54)$ & 0.01 \\
\hline Successful reperfusion at the end of the procedure & $313(98.1)$ & $128(98.5)$ & $185(97.9)$ & 1.00 \\
\hline Parenchymal hematoma type 2 & $14(4.4)$ & $9(6.9)$ & $5(2.6)$ & 0.067 \\
\hline $90 \mathrm{~d}$ mRS $0-2$ & $100(44.6)$ & $38(44.2)$ & $62(44.9)$ & 0.91 \\
\hline $90 \mathrm{~d}$ mortality & $42(18.8)$ & $14(16.3)$ & $28(20.3)$ & 0.45 \\
\hline
\end{tabular}


Abstract E-062 Table 2 Predictors of FPE (mTICl2c-3)

\begin{tabular}{llll}
\hline & Odds ratio & $95 \% \mathrm{Cl}$ & P value \\
\hline Irregular occlusion shape & 1.756 & $1.049-2.940$ & 0.03 \\
ASPECTS & 1.151 & $0.982-1.348$ & 0.08 \\
Hyperlipidemia & 1.697 & $0.976-2.953$ & 0.06 \\
\hline
\end{tabular}

rates of FPE and functional independence (90-day mRS 0-2). Uni- and multivariable analyses were performed to identify predictors of FPE. A secondary analysis was the interaction between the first line MT technique and the shape of occlusion on the FPE.

Results A total of 319 were included in the analysis, the mean age was 65.1 years, $168(52.7 \%)$ were females. Median [IQR] baseline NIHSS score was 17 [12-21] and ASPECTS was 8 [79]. Patients with the regular shape of occlusion had a significantly higher frequency of smoking $(28.5 \%$ vs. $18.5 \%$, $\mathrm{p}=0.037)$. Cardioembolic strokes were more frequently presented with the regular shape of occlusion (53.1\% vs. $43.9 \%)$. Conversely, intracranial atherosclerosis was significantly associated with irregular shape of occlusion $(13.2 \%$ vs. $6 \%), p=0.04$. Irregular occlusion shape had significantly lower median number of MT passes to achieve successful reperfusion (1 [1-2] vs. 2 [1-3], $\mathrm{p}=0.01$ and higher rates of FPE $46 \%$ vs. $34.6 \%$, $\mathrm{p}=0.04)$ and a trend to lower rates of parenchymal hematoma type $2(2.6 \%$ vs. $6.9 \%, p=0.067)$. There was no significant interaction between first-line MT technique and the shape of occlusion on FPE. Functional independence and 90-day mortality were similar between the two groups. On multivariable analysis, the irregular shape of occlusion was an independent predictor of FPE (OR 1.756; 95\% CI[1.049-2.940], $p=0.03$ ).

Conclusions The angiographic shape of M1 occlusion is a predictor of FPE. Large prospective multicenter studies are warranted for a better understanding of whether the occlusion appearance guides the selection of the MT techniques and hence potentially increase the chance of FPE.

Disclosures M. Mohammaden: None. D. Haussen: 2; C; Stryker, Vesalio. 4; C; Viz.AI. L. Pisani: None. A. Al-Bayati: None. S. Belagaje: None. N. Bhatt: None. M. Frankel: None.
R. Nogueira: 2; C; Phenox, Anaconda, Genentech, Brainomix, Viz-AI

\section{\begin{tabular}{|l|l}
\hline E-063 PRIMARY RESULTS FROM THE PREDICT (PRE-HOSPITAL \\
\hline
\end{tabular} EMERGENCY LVO DETECTION DURING INITIAL CARE TRANSPORT) STUDY: A PROSPECTIVE, MULTI-CENTER, NON-INFERIORITY COMPARISON BETWEEN THE NOVEL PREDICT COMPOSITE 4-ITEM SCALE AND THE RAPID ARTERIAL OCCLUSION EVALUATION (RACE) SCALE TO DETECT LARGE-VESSEL OCCLUSION (LVO) STROKES WHEN ADMINISTERED BY US-BASED EMS PERSONNEL TO SUSPECTED STROKE PATIENTS AT THE INITIAL PRE-HOSPITAL ENCOUNTER}

${ }^{1} \mathrm{R}$ James $I \|^{*},{ }^{1} \mathrm{~A}$ Cruz, ${ }^{1} \mathrm{E}$ Fortuny, ${ }^{1} \mathrm{~B}$ Ugiliweneza, ${ }^{1} \mathrm{D}$ Wang, ${ }^{2} \mathrm{~A}$ White, ${ }^{1} \mathrm{~N}$ Khattar, ${ }^{1} \mathrm{~S}$ Adams, ${ }^{1} \mathrm{~B}$ Gallinore, ${ }^{1} \mathrm{D}$ Ding, ${ }^{3} \mathrm{~S}$ Wolfe, ${ }^{4} \mathrm{D}$ Heck. ${ }^{1}$ Neurosurgery, University of Louisville, Louisville, KY; ${ }^{2}$ Radiology, University of Louisville, Louisville, KY; ${ }^{3}$ Neurosurgery, Wake Forest Baptist Health, Lexington, NC, ${ }^{4}$ Radiology, Forsythe Medical Center, Winston-Salem, NC

\subsection{6/neurintsurg-2020-SNIS.99}

Introduction Accurate identification of large vessel occlusion (LVO) strokes in the pre-hospital setting is imperative to reduce time to thrombectomy and improve outcomes. Prior to this study, RACE was the only stroke severity scale designed to detect LVO that had been prospectively validated with Emergency Medical Services (EMS). The goal of our non-inferiority study is to prospectively validate and compare the novel PREDICT-3 item scale, PASS scale, and a composite of these two scales: the PREDICT Composite 4-item (PREDICT4) scale to the RACE scale in detecting LVO in the prehospital setting.

Methods Adult patients suspected of having a stroke by EMS and transported to a participating comprehensive stroke center had both PREDICT-4 and RACE scales administered prospectively and recorded in a secure web-based database. Admission NIHSS score and final diagnosis were also recorded. Cerebrovascular imaging studies (CTA, MRA or DSA) were reviewed by a blinded, independent neuroradiologist to determine LVO diagnosis. LVO was defined as occlusion of intracranial internal carotid artery (ICA), middle cerebral artery (MCA) M1
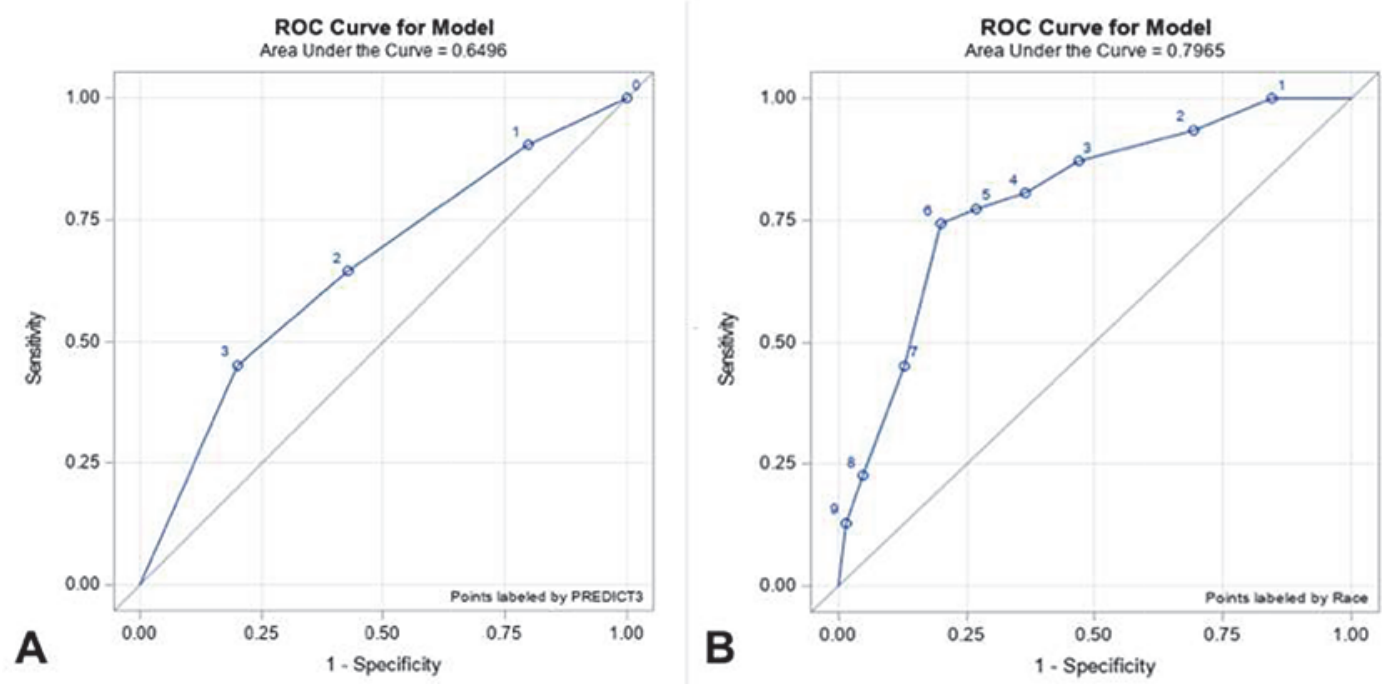

Abstract E-063 Figure 1A Receiver Operating Characteristic (ROC) curve illustrating the sensitivity, specificity and area under the curve of the PREDICT-3 scale. 1B Receiver Operating Characteristic (ROC) curve illustrating the sensitivity, specificity and area under the curve of the RACE Scale 